\title{
ESPAÇO, TERRITÓRIO E PAISAGEM: uma leitura teórico- metodológica da Geografia Agrária brasileira na pós-graduação a partir dos anos $1970^{1}$
}

\author{
SPACE, TERRITORY AND LANDSCAPE: a theoretical and \\ methodological reading of brazilian rural geography in \\ Graduate Programs from the 1970s
}

\author{
Darlene Aparecida de Oliveira Ferreira \\ DEGEOG-IGCE-UNESP-Rio Claro-SP; darlene@rc.unesp.br \\ Maria Ribeiro do Valle \\ DSOC-FCLAR-UNESP-Araraquara-SP; maria.ribeiro.valle@uol.com.br \\ Vera Lúcia Salazar Pessôa \\ UFU - Uberlândia-MG; verinha.salazar@hotmail.com \\ Maria José Romanatto \\ DCED-FCLAR-UNESP-Araraquara-SP; maze@fclar.unesp.br \\ Glaucio José Marafon \\ IGEOG-UERJ-RJ; glauciomarafon@hotmail.com
}

\section{Resumo}

O objetivo desse trabalho foi propor uma leitura teórico-metodológica da geografia agrária brasileira nos Programas de Pós-Graduação em Geografia (PPGEO’s) da Região Sudeste, a partir dos anos 1970, procurando apresentar uma discussão sobre as categorias de análise (espaço, território, paisagem, região e lugar) que vem sendo desencadeada ao longo dos Encontros de Geografia Agrária (ENGA's) e, nos três Encontros de Grupos de Pesquisa de Geografia Agrária (2005, 2006, 2007). Assim, partiu-se da hipótese de que a relativização dos conceitos científicos pode comprometer a elaboração de conceitos apenas geográficos. Para cumprir o objetivo proposto realizou-se um levantamento de dissertações e teses, defendidas no período de 1970 a 2009, nos Programas de Pós-Graduação em Geografia da UFMG e UFU (Minas Gerais); UFRJ, UFF e UERJ (Rio de Janeiro) e USP, UNESP/Rio Claro, UNESP/Presidente Prudente (São Paulo). A avaliação realizada tratou as informações quantitativas e traçou um perfil da Geografia Agrária. De forma qualitativa, o aprofundamento da análise, cruzando as informações, contextualizando os temas e, principalmente, avaliando o conjunto teórico referenciado nos trabalhos, permitiu a indicação dos caminhos seguidos por esse ramo da Geografia brasileira para os quais se 
observa que nas referências às categorias o espaço e, mais precisamente a organização do espaço, foi priorizada nos anos 1980 e o território como referência dos trabalhos pós 1990.

Palavras-chave: Espaço. Território. Paisagem. Programas de Pós-Graduação em Geografia/SE.

\begin{abstract}
The aim of this study was to propose a reading of theoretical and methodological geography of Brazilian agriculture in Post-Graduate Studies in Geography (PPGE's) from the Southeast, from the 1970s, trying to present a discussion of the analysis categories (space, territory, landscape, region and place) that has been unleashed over the meetings of Agrarian Geography (ENGA's) and in three meetings of the Research Groups of Agrarian Geography (2005, 2006, 2007). So, we started with the hypothesis that the relativization of scientific concepts may impair development of spatial concepts only. To accomplish our objective we carried out a survey of dissertations and theses supported in the period 1970 to 2009, in Post-Graduate in Geography and UFU UFMG (Minas Gerais), UFRJ, UFF and UERJ (Rio de Janeiro) and USP, UNESP / Rio Claro, UNESP / Presidente Prudente (Sao Paulo). The evaluation dealt with the quantitative and drew a profile of Agrarian Geography. Qualitatively, further analysis, crossing information, contextualizing the themes and especially evaluating the theoretical set referenced in the works, an indication of the possible paths followed by this branch of the Brazilian Geography for which it is observed that the references to the categories space and, more specifically the organization of space, was prioritized in the 1980s and the territory as a reference work after 1990.
\end{abstract}

Key words: Space. Territory. Landscape. Graduate Programs in Geography/SE (Brazil).

\title{
Introdução
}

O ponto de partida desse trabalho foi a investigação das fontes teóricometodológicas utilizadas na Geografia Agrária, pela equipe dos pesquisadores em seus Encontros Nacionais de Geografia Agrária (ENGA's) e nos três Encontros de Grupos de Pesquisa de Geografia Agrária realizados, respectivamente, na UERJ (2005), UFU (2006) e UFRGS (2007) ${ }^{2}$.

Embora, nesses eventos, as categorias de análise (espaço, território e paisagem) e os princípios lógicos (localização, distribuição, extensão, distância, posição e escala) da Geografia sejam sempre retomados, notamos uma ausência de reflexão acerca do referencial teórico-metodológico que lhes dá suporte.

Partimos do pressuposto de que apesar dos avanços trazidos pelo pluralismo metodológico que caracteriza o mundo acadêmico atual, ele também pode estar impedindo uma delimitação mais precisa dos princípios e categorias específicos de cada 
área do conhecimento. Ou seja, partimos da hipótese de que a relativização dos conceitos científicos pode desembocar no comprometimento de elaboração de conceitos mais genuinamente geográficos, no caso dessa pesquisa.

Para que o estudo pudesse construir um cenário da Geografia Agrária Brasileira foi necessário delinear dois tipos de preocupação: a) o conhecimento do objeto de análise, isto é, a produção geográfica em programas de pós-graduação, em nosso caso, programas situados na região Sudeste brasileira.

A situação atual foi analisada tendo em vista: estudo formal estatístico/documental, através do levantamento de dissertações e teses; análise do conteúdo - temas, categorias de análise; periodização e identificação das tendências.

O processo de investigação para compreender o significado das categorias espaço, território e paisagem nas dissertações e teses dos PPGEO’s exigiu levantamento e armazenamento das informações coletadas nas dissertações e teses defendidas a partir da década de 1970 nos Programas de Pós-Graduação em Geografia das Universidades de Minas Gerais (UFMG/UFU), de São Paulo (USP/UNESP/Rio Claro e Presidente Prudente e do Rio de Janeiro (UFRJ, UFF, UERJ).

Para identificação das dissertações e teses de Geografia, utilizamos a seguinte categorização: trabalhos cujos títulos, palavras-chave, resumo e ainda aqueles desenvolvidos junto a linhas de pesquisa dos Programas tenham como tema o AGRO e orientadores que desenvolvem pesquisas em Geografia Agrária e que circulam por eventos como ENGA, ENGRUP, ANPEGE e ENG.

Na pesquisa realizada identificou-se, além da diversidade de seu objeto, uma Geografia Agrária com características temporais distintas. Os Programas estudados têm histórias diversas de formação e seus tempos de vida são discrepantes. Investigamos o primeiro Programa de Pós-Graduação em Geografia do Brasil, que tem os níveis de mestrado e doutorado já consolidados. Estudamos também os não menos importantes Programas que, por serem novos, têm apenas o nível de mestrado em funcionamento.

Estas discrepâncias refletem-se nos números de trabalhos encontrados, como se verá mais adiante. Não há programa mais produtivo que outro, mas também não há dúvida que o que define o número de dissertações e teses em Geografia Agrária no Programa é o número de orientadores presentes. 


\section{Um “olhar” sobre a geografia agrária nas dissertações e teses dos Programas de Pós-Graduação a partir da década de 1970}

O trabalho buscou aspectos quantitativos e qualitativos sobre o número de dissertações e teses defendidas nos referidos Programas, cobrindo o período de 1970 a 2009, identificando o número de estudos efetuados sobre agricultura em suas diversas abordagens: agrária; agrícola e rural. A análise realizada permite traçar um perfil dos estudos realizados sobre o temário da Geografia Agrária nos Programas de PósGraduação em Geografia da região SUDESTE.

Do total de mais de 1500 dissertações e teses defendidas até o ano de 2009, 438 realizaram estudos referentes à Geografia Agrária, conforme demonstra a tabela 1 que apresenta o número total de dissertações e teses levantado. Observa-se a significativa predominância do Estado de São Paulo, particularmente da Universidade de São Paulo, como produtor de conhecimento na Geografia Agrária. Vale lembrar que o Programa de Pós Graduação em Geografia da USP foi o primeiro a ser institucionalizado no Brasil. Se compararmos cada instituição, isoladamente, notamos que a UNESP-Rio Claro apresenta-se também como uma das mais importantes produtoras de conhecimento na área da Geografia Agrária.

Tabela 1 - Número de dissertações e teses em geografia agrária - 1970-2009

\begin{tabular}{l|l|c|c|c}
\hline \multirow{2}{*}{ Estado } & \multirow{2}{*}{ I. E. S. } & \multicolumn{2}{c|}{ Nível } & \multirow{2}{*}{ Total } \\
\cline { 3 - 4 } & & Doutorado & Mestrado & \\
\hline \multirow{2}{*}{ Minas Gerais } & UFMG & - & 14 & 14 \\
& UFU & 4 & 23 & 27 \\
\multirow{5}{*}{ Rio de Janeiro } & UERJ & - & 9 & 9 \\
& UFF & 3 & 14 & 17 \\
& UFRJ & 10 & 32 & 42 \\
São Paulo & UNESP - PP & 16 & 30 & 46 \\
& UNESP - Rio Claro & 33 & 51 & 84 \\
\hline Total & USP & 76 & 123 & 199 \\
\hline
\end{tabular}

Fonte: Dissertações e teses em geografia agrária/ USP / UNESP-RC / UNESP-PP / UERJ / UFF/UFRJ / UFU /UFMG.

Org. FERREIRA, D. Ap. O; VALLE, M. R.; ROMANATTO, M. J., 2010.

Nas dissertações e teses estudadas identificamos que na década de 1980, a presença dos estudos agrários é marcante entre os mestrados, considerando-se que o número de alunos e orientadores ainda é reduzido e o doutorado ganhará força na 
década seguinte. É o período mais rico de produção na temática, em contexto nacional. Rio Claro ganha destaque pelo desenvolvimento de trabalhos na área da Geografia Quantitativa, pela participação nos Encontros Nacionais de Geografia Agrária - tendo, inclusive, em seu corpo docente membros criadores do curso de Pós-Graduação e pela produção de seus docentes, repercutindo na procura pelo Programa e, particularmente, pela Geografia Agrária.

Há um declínio no número desses estudos na primeira metade da década de 1990, sendo que a frequência de trabalhos continua diminuindo, de forma significativa, a partir da segunda metade da referida década. Os fatores primordiais desse processo de declínio no número de trabalhos são a aposentadoria de orientadores da área de Geografia Agrária e o surgimento de outras temáticas que dividem a atenção dos pósgraduandos.

Na década de 1990, as teses de doutorado distribuíram-se mais uniformemente, havendo no final da década uma oscilação positiva. Em relação aos orientadores, encontramos o mesmo comportamento, ou seja, uma distribuição mais uniforme, com destaque para um caso de maior frequência de orientações. Permanecem os mesmos orientadores encontrados para o mestrado. Também é possível observar a presença de orientadores de doutorado em pesquisas sobre o agro, mas que não têm como fundamentos os dispositivos da Geografia Agrária, mas sim da geomorfologia, da agroclimatologia e da percepção/fenomenologia.

Na tabela 2, ao analisarmos a distribuição por décadas - de 1970 a de 2000 -, notamos que o Programa de Pós-Graduação de Geografia Humana da USP é o primeiro a se constituir, mantendo-se com uma regularidade de defesas de dissertações e teses ao longo de todo o período. Embora o Programa da UFRJ seja o próximo a ser criado, ele apresenta uma pequena produção em geografia agrária no mesmo período. Já o Programa de Rio Claro que terá sua primeira defesa na década de 1980, apresenta uma oscilação ao longo das décadas, sendo muito significativa em alguns anos e pouco expressiva em outros, particularmente, na década de 2000.

Os Programas mais recentes - UFMG, UFU, UFF, UNESP/PP, UERJ - têm como característica peculiar uma oscilação da produção de dissertações e teses, com exceção da UNESP/PP que possui destaque no número de trabalhos defendidos. A década de 2000 apresenta Programas - USP e UNESP/PP - que ultrapassam uma dezena 
de defesas. Esses números evidenciam que a agricultura, sob distintas abordagens, é temática de interesse dos geógrafos definindo, para o Brasil, um dos ramos mais significativos da Geografia no país.

Tabela 2 - Distribuição dos Programas de Pós-Graduação em Geografia na região Sudeste a partir da década de 1970

\begin{tabular}{l|c|c|c|c}
\hline \multirow{2}{*}{ Programas } & \multicolumn{4}{|c}{ Décadas } \\
\cline { 2 - 5 } UFMG & $\mathbf{1 9 7 0}$ & $\mathbf{1 9 8 0}$ & $\mathbf{1 9 9 0}$ & $\mathbf{2 0 0 0}$ \\
UFU & & & $\mathrm{X}$ & $\mathrm{X}$ \\
UFRJ & & & & $\mathrm{X}$ \\
UFF & $\mathrm{X}$ & $\mathrm{X}$ & $\mathrm{X}$ & $\mathrm{X}$ \\
UERJ & & & $\mathrm{X}$ \\
USP & & & $\mathrm{X}$ & $\mathrm{X}$ \\
UNESP - Rio Claro & $\mathrm{X}$ & $\mathrm{X}$ & $\mathrm{X}$ & $\mathrm{X}$ \\
UNESP - Presidente Prudente & & $\mathrm{X}$ & $\mathrm{X}$ & $\mathrm{X}$ \\
\hline
\end{tabular}

Fonte: Dissertações e teses em geografia agrária / USP / UNESP-RC / UNESP-PP / UERJ / UFF/UFRJ / UFU /UFMG.

Org. FERREIRA, D. Ap. O; VALLE, M.R.; ROMANATTO, M. J., 2010.

\section{Palavras-chave e temáticas das dissertações e teses em geografia agrária}

Com relação à análise das palavras-chave, foi possível identificar os temas especialmente importantes escolhidos para servir de referência às dissertações e teses. De modo geral, nota-se a presença de três grandes grupos de palavras:

1. Aquelas diretamente relacionadas ao setor agropecuário em suas distintas facetas - sociais (agrários) e econômicas (agrícola);

2. Aquelas ligadas às discussões sobre o desenvolvimento;

3. Aquelas que referenciam locais estudados.

A referência ao estado e políticas públicas, ao meio ambiente e à sustentabilidade aparecem como novas tendências, com destaque para os programas como da UFMG e da UFF. Espaço, território, paisagem, região são categorias geográficas que aparecem pouco referenciadas. 
As referências ao agrário/agrária nas dissertações estão vinculadas aos estudos sobre o espaço e a estrutura do setor agropecuário e aparecem nos trabalhos dos anos 1980. O agrícola é usado para adjetivar as palavras espaço, geografia, políticas, fronteira e atividade, citadas ao longo do período que estudamos. O rural prevalece ao longo da década de 1980 e define um tipo de trabalhador, uma economia, um meio e um tipo de desenvolvimento.

Nas teses, o agrário/agrária adjetiva espaço e geografia ao longo da década de 1980. O agrícola aparece nos anos 1990 e define sistema, política e cooperação. Na fase mais recente de nossa análise, pós-meados dos anos 1990, o rural evidencia espaço predominantemente como referência de localização, ou seja, local onde ocorre o turismo rural, por exemplo.

Quando tomamos todas as palavras citadas nas 142 dissertações e 296 teses e medimos a frequência - destacamos as palavras que foram citadas até três vezes, a partir daí, com 2 ou 1 citação há uma lista ampla de referências - podemos inferir que a modernização da agricultura foi um marco nos estudos de Geografia Agrária na PósGraduação em Geografia. O período de implantação de vários cursos correspondente às fases de surgimento e de desenvolvimento desse processo de modernização traz para pós-graduandos um tema de pesquisa, bem como os impactos de tal fenômeno, atrelados ainda à agroindústria e ao desenvolvimento rural.

Logicamente, a agricultura é referenciada tendo-se em vista que o ramo da Geografia que estudamos tem como objeto de estudo essa atividade, e a organização do espaço evidencia o “olhar” geográfico sobre o agro. A partir da década de 1970 o Estado torna-se referência de análise para os doutorandos explicada pelo aporte do Estado como agente organizador do espaço agrícola, agrário e rural.

Com relação às culturas, soja e cana-de-açúcar são evidenciadas. Primeiro, pelo seu papel no processo de modernização da agricultura, processo esse estudado, e segundo, pela representação no conjunto da agroindústria. Os locais estudados são citados e estão pulverizados no conjunto total das palavras.

O escopo foi o conjunto de palavras-chave indicadas pelos autores das 438 dissertações e teses dos Programas de Pós-Graduação avaliados nesta pesquisa. Examinaremos os resultados a partir de cada nível dos Programas divididos por Estados componentes da região Sudeste. Antes de efetuarmos a descrição e análise das palavras- 
chave, gostaríamos de esclarecer que estaremos considerando as categorias geográficas - espaço, território, paisagem, região - e tratando da temática da agricultura em suas diversas abordagens - agrária; agrícola e rural. Será possível observar que não há uma palavra que se destaque de forma isolada, há uma dispersão dos assuntos tratados nas dissertações e teses, o que é possível se observar no conjunto de palavras indicadas apenas uma vez.

\section{MINAS GERAIS}

\section{a) UFU}

Na tabela 3 destaca-se o fato de que a “Geografia Rural” é uma expressão utilizada como palavra-chave por quatro autores de dissertações; ocorrência pouco freqüente no conjunto da pesquisa.

Tabela 3 - Palavras-chave nas dissertações em geografia agrária do PPGEO/UFU

\begin{tabular}{l|c}
\hline Palavias-chave & Total \\
\hline Agricultura familiar & 10 \\
Modernização da agricultura & 6 \\
Geografia rural & 4 \\
Agroindústria & 3 \\
Assentamento rural & 3 \\
Comunidade rural & 3 \\
Reforma agrária & 3 \\
Associativismo rural & 2 \\
Desenvolvimento sustentável & 2 \\
Luta pela terra & 2 \\
Território & 2 \\
Outras & 1 \\
Total & $\mathbf{4 1}$ \\
\hline
\end{tabular}

Fonte: Dissertações e teses em geografia agrária / USP / UNESP-RC / UNESP-PP / UERJ / UFF/UFRJ / UFU /UFMG.

Org. FERREIRA, D. Ap. O; VALLE, M. R.; ROMANATTO, M. J., 2010.

A presença das categorias geográficas como palavras-chave não é significativa. Dentre as palavras-chave que mais se destacam apenas território aparece.

Com relação à temática da agricultura e suas diversas abordagens encontramos palavras-chave dentre as quais se destacam: agricultura familiar e modernização da agricultura.

Na tabela 4 destaca-se o fato de que temos apenas uma palavra-chave citada mais do que uma vez: políticas públicas. A presença das categorias geográficas como 
palavras-chave também não é significativa. Apenas são mencionadas as seguintes: (re)ordenamento territorial, identidade territorial, reterritorialização.

Com relação à temática da agricultura e suas diversas abordagens encontramos apenas as palavras-chave: agroindústria canavieira, modernização da agricultura e campesinato.

Tabela 4 - Palavras-chave nas teses em geografia agrária do PPGEO/UFU

\begin{tabular}{l|c}
\hline Palavras-chave & Total \\
\hline Políticas públicas & 2 \\
Outras & 1 \\
\hline Total & $\mathbf{3}$ \\
\hline
\end{tabular}

Fonte: Dissertações e teses em geografia agrária / USP / UNESP-RC / UNESP-PP / UERJ / UFF/UFRJ / UFU /UFMG.

Org. FERREIRA, D. Ap. O; VALLE, M. R.; ROMANATTO, M. J., 2010.

\section{b) UFMG}

Na tabela 5, destaca-se a presença da palavra-chave sustentabilidade com variantes para o desenvolvimento rural. Nela não estão presentes as categorias geográficas como palavras-chave.

Com relação à temática da agricultura e suas diversas abordagens se destaca-se agricultura familiar.

Tabela 5 - Palavras-chave nas dissertações em geografia agrária do PPGEO/UFMG

\begin{tabular}{l|c}
\hline Palavras-chave & Total \\
\hline Agricultura familiar & 8 \\
Sustentabilidade & 4 \\
Comunidades rurais & 2 \\
Políticas Públicas & 2 \\
Produção familiar de leite & 2 \\
Outras & 1 \\
\hline \multicolumn{1}{l}{ Total } & $\mathbf{1 9}$ \\
\hline
\end{tabular}

Fonte: Dissertações e teses em geografia agrária / USP / UNESP-RC / UNESP-PP / UERJ / UFF/UFRJ / UFU /UFMG.

Org. FERREIRA, D. Ap. O; VALLE, M. R.; ROMANATTO, M. J., 2010.

\section{RIO DE JANEIRO}

\section{a) UERJ}

Na tabela 6 destaca-se o fato de que a única palavra-chave citada mais de uma vez refere-se à categoria geográfica: território. Podemos ainda chamar a atenção para a 
presença de outras categorias geográficas utilizadas como palavras-chave: paisagem, região e rede. E as variantes: espaço agrário e interações espaciais.

Com relação à temática da agricultura e suas diversas abordagens encontramos palavras-chave dentre as quais se destacam: agricultura familiar, assentamento rural e pluriatividade.

Tabela 6 - Palavras-chave nas dissertações em geografia agrária do PPGEO/UERJ

\begin{tabular}{l|c}
\hline Palavras-chave & Total \\
\hline Território & 2 \\
Outras & 1 \\
\hline Total & $\mathbf{3}$ \\
\hline
\end{tabular}

Fonte: Dissertações e teses em geografia agrária / USP / UNESP-RC / UNESP-PP / UERJ / UFF/UFRJ / UFU /UFMG.

Org. FERREIRA, D. Ap. O; VALLE, M. R.; ROMANATTO, M. J., 2010.

\section{b) UFF}

Na tabela 7 destaca-se a presença das categorias geográficas: território e rede, acompanhadas ainda das expressões ordenamento territorial e territorialidade.

Com relação à temática da agricultura e suas diversas abordagens encontramos palavras-chave como: agronegócio, circulação/transporte, comercialização e produção agrícola, temas clássicos nos estudos de agricultura.

Tabela 7 - Palavras-chave nas dissertações em geografia agrária do PPGEO/UFF

\begin{tabular}{l|c}
\hline Palavras-chave & Total \\
\hline Território & 4 \\
Rede & 3 \\
Corporação & 2 \\
Ordenamento Territorial & 2 \\
Outras & 1 \\
\hline Total & 12 \\
\hline
\end{tabular}

Fonte: Dissertações e teses em geografia agrária / USP / UNESP-RC / UNESP-PP / UERJ / UFF/UFRJ / UFU /UFMG.

Org. FERREIRA, D. Ap. O; VALLE, M. R.; ROMANATTO, M. J., 2010.

Na tabela 8 destaca-se o fato de que todas as palavras-chave são citadas apenas uma vez e que há uma freqüente referência aos locais estudados. Com relação à temática da agricultura encontramos as palavras-chave: agroindústria e campesinato. 
Tabela 8 - Palavras-chave nas teses em geografia agrária do PPGEO/UFF

\begin{tabular}{l|c}
\hline Palavias-chave & Total \\
\hline Agroindústria & 1 \\
Campesinato & 1 \\
Canudos & 1 \\
Conflito & 1 \\
Desenvolvimento & 1 \\
Dinâmica sócio-espacial & 1 \\
Espírito Santo & 1 \\
Goiás & 1 \\
MST & 1 \\
Relação campo-cidade & 1 \\
Territorialidade & 1 \\
\hline Total & $\mathbf{1 1}$
\end{tabular}

Fonte: Dissertações e teses em geografia agrária / USP / UNESP-RC / UNESP-PP / UERJ / UFF/UFRJ / UFU /UFMG.

Org. FERREIRA, D. Ap. O; VALLE, M. R.; ROMANATTO, M. J., 2010.

\section{c) UFRJ}

Na tabela 9 destaca-se o fato de que a "Geografia Agrária” é uma expressão utilizada como palavra-chave por quatro autores de dissertações. Merece destaque também a palavra técnica, o que evidencia no programa uma tendência à valorização desta temática no contexto da agroindústria e do agronegócio.

As categorias geográficas espaço e território vêm acompanhadas das expressões espaço agrário, gestão do território, organização do espaço e organização espacial. Escala é outra importante referência geográfica presente.

Com relação à temática da agricultura destacam-se: agroindústria; pequena produção; agronegócio e culturas como cana-de-açúcar, soja, horticultura, e ainda, pecuária leiteira. Destaque também deve ser feito para as referências a locais pesquisados: Mato Grosso, Rio de Janeiro, Alagoas, São Paulo.

Tabela 9 - Palavras-chave nas dissertações em geografia agrária do PPGEO/ UFRJ

(Continua)

\begin{tabular}{l|c}
\hline Palavras-chave & Total \\
\hline Geografia Agrária & 4 \\
Técnica & 4 \\
Agroindústria & 3
\end{tabular}


Tabela 9 - Palavras-chave nas dissertações em geografia agrária do PPGEO/ UFRJ

(Conclusão)

\begin{tabular}{l|c}
\hline Palavras-chave & Total \\
\hline Espaço agrário & 3 \\
Mato Grosso & 3 \\
Modernização da agricultura & 3 \\
Pequena produção & 3 \\
Rio de Janeiro & 3 \\
Agronegócio & 2 \\
Alagoas & 2 \\
Cana-de-açúcar & 2 \\
Espaço & 2 \\
Fronteira & 2 \\
Gestão do Território & 2 \\
Horticultura & 2 \\
Pecuária leiteira & 2 \\
São Paulo & 2 \\
Soja & 2 \\
Território & 2 \\
Trabalho & 2 \\
Outras & 1 \\
\hline Total & $\mathbf{5 1}$ \\
\hline
\end{tabular}

Fonte: Dissertações e teses em geografia agrária / USP / UNESP-RC / UNESP-PP / UERJ / UFF/UFRJ / UFU /UFMG.

Org. FERREIRA, D. Ap. O; VALLE, M. R.; ROMANATTO, M. J., 2010.

Na tabela 10 agricultura e assentamento rural são destaques. A presença das categorias geográficas e suas variantes: paisagem geográfica, espaço rural, organização territorial, gestão do território é visível. Com relação à temática da agricultura se destacam: produção rural, pequeno produtor e produtividade.

Tabela 10 - Palavras-chave nas teses em geografia agrária do PPGEO/UFRJ

\begin{tabular}{l|c}
\hline Palavras-chave & Total \\
\hline Agricultura & 2 \\
Assentamento rural & 2 \\
Outras & 1 \\
\hline Total & $\mathbf{5}$ \\
\hline
\end{tabular}

Fonte: Dissertações e teses em geografia agrária / USP / UNESP-RC / UNESP-PP / UERJ / UFF/UFRJ / UFU /UFMG.

Org. FERREIRA, D. Ap. O; VALLE, M. R.; ROMANATTO, M. J., $2010 .$.

\section{SÃO PAULO}

\section{a) UNESP - Presidente Prudente}

Como mostra a tabela 11, o Programa de Pós-Graduação de Presidente Prudente apresenta como peculiaridade, por um lado, estudos que revelam preocupação com a 
“questão agrária”. Isto está evidenciado na palavra-chave mais referenciada em suas dissertações: assentamento rural, bem como nas seguintes: campesinato e luta pela terra. Por outro lado, a modernização da agricultura e pequeno produtor, são outras palavraschave freqüentes.

A presença das categorias geográficas é demarcada pela indicação da palavrachave território e sua derivada territorialidade. Há referência ao espaço num contexto de reorganização espacial.

Tabela 11- Palavras-chave nas dissertações em geografia agrária do PPGEO/UNESP/Presidente Prudente

\begin{tabular}{l|c}
\hline Palavras-chave & Total \\
\hline Assentamento Rural & 6 \\
Impactos socioterritoriais & 4 \\
Modernização da agricultura & 4 \\
Pequeno produtor & 4 \\
Território & 4 \\
Agricultura familiar & 3 \\
Campesinato & 3 \\
Estratégia de reprodução social & 3 \\
Luta pela terra & 3 \\
Pequena propriedade & 3 \\
Associação de produtores & 2 \\
Cooperativas & 2 \\
Exclusão & 2 \\
Identidade camponesa & 2 \\
Ocupação & 2 \\
Pluriatividade & 2 \\
Reforma Agrária & 2 \\
Outras & 1 \\
\hline Total & $\mathbf{5 2}$ \\
\hline
\end{tabular}

Fonte: Dissertações e teses em geografia agrária / USP / UNESP-RC / UNESP-PP / UERJ / UFF/UFRJ / UFU /UFMG.

Org. FERREIRA, D. Ap. O; VALLE, M. R.; ROMANATTO, M. J., 2010.

Na tabela 12, as palavras-chave indicadas nas teses revelam a importância atribuída à questão agrária refletida por palavras-chave como: reforma agrária, luta pela terra, assentamento rural e a própria questão agrária. Nota-se também uma preocupação com a metodologia que é referenciada como palavra-chave e tema privilegiado em nosso estudo.

O território aparece como categoria geográfica referenciada, bem como os seus derivados territorialidade (palavra-chave mais citada) e desenvolvimento territorial. Temos ainda referências à escala, narrativa escalar e lugar. Com relação à temática da 
agricultura temos particularmente as palavras-chave agroecologia e agricultura sustentável de um lado e agroindústria, de outro.

Tabela 12 - Palavras-chave nas teses em geografia agrária do PPGEO/UNESP/Presidente Prudente

\begin{tabular}{l|c}
\hline Palavras-chave & Total \\
\hline Territorialidade & 4 \\
Agricultura familiar & 3 \\
Agroecologia & 3 \\
Assentamento rural & 3 \\
Questão agrária & 3 \\
Reforma agrária & 3 \\
Território & 3 \\
Agricultura Sustentável & 2 \\
Agroindústria & 2 \\
Escala & 2 \\
Luta pela Terra & 2 \\
Metodologia & 2 \\
Outras & 1 \\
\hline Total & $\mathbf{3 3}$ \\
\hline
\end{tabular}

Fonte: Dissertações e teses em geografia agrária / USP / UNESP-RC / UNESP-PP / UERJ / UFF/UFRJ / UFU /UFMG.

Org. FERREIRA, D. Ap. O; VALLE, M. R.; ROMANATTO, M. J., 2010.

\section{b) UNESP - Rio Claro}

Na tabela 13 destaca-se o fato de que a "Geografia Agrícola” é uma expressão utilizada como palavra-chave por três autores de dissertações e que está intrinsecamente relacionada com as três principais palavras-chave citadas: modernização da agricultura, agricultura e agroindústria. Também podemos destacar a presença de palavras que referenciam culturas: café, soja e cana-de-açúcar.

Com relação às categorias geográficas destaca-se a palavra-chave território e a expressão organização do espaço.

Tabela 13 -Palavras -chave nas dissertações em geografia agrária do PPGEO/UNESP/Rio Claro

(Continua)

\begin{tabular}{l|c}
\hline Palavras-chave & Total \\
\hline Modernização da agricultura & 13 \\
Agricultura & 9 \\
Agroindústria & 8
\end{tabular}


Tabela 13 -Palavras -chave nas dissertações em geografia agrária do PPGEO/UNESP/Rio Claro

(Conclusão)

\begin{tabular}{l|c}
\hline Palavras-chave & Total \\
\hline Organização do Espaço & 6 \\
Café & 5 \\
Desenvolvimento Rural & 5 \\
Pequeno Produtor & 5 \\
Cana-de-Açúcar & 4 \\
Álcool & 3 \\
Campesinato & 3 \\
Cartografia & 3 \\
Fronteira Agrícola & 3 \\
Geografia Agrícola & 3 \\
Ocupação do Espaço & 3 \\
Rio Claro (SP) & 3 \\
Soja & 3 \\
Trabalhador Rural & 3 \\
Açúcar & 2 \\
Agricultura Familiar & 2 \\
Citricultor & 2 \\
Espaço Rural & 2 \\
Migração & 2 \\
Pecuária & 2 \\
Pequena Propriedade & 2 \\
Produtividade Agrícola & 2 \\
São Paulo & 2 \\
Território & 2 \\
Uso da Terra & 2 \\
Outras & 1 \\
\hline Total & 105 \\
\hline
\end{tabular}

Fonte: Dissertações e teses em geografia agrária / USP / UNESP-RC / UNESP-PP / UERJ / UFF/UFRJ / UFU /UFMG.

Org. FERREIRA, D. Ap. O; VALLE, M. R.; ROMANATTO, M. J., 2010.

Na tabela 14 permanecem em evidência as palavras-chave: agricultura, Estado e modernização da agricultura.

É o primeiro nível de Programa de Pós Graduação onde há a presença de todas as categorias geográficas apesar de variar a sua frequência. São elas: espaço agrário (3), espaço rural (3), região (2), território (2), lugar (1), organização do espaço (1), paisagem rural (1), produção do espaço (1).

Merece destaque também que este é o único programa em que o turismo é referenciado como palavra-chave, evidenciando, ao lado da bibliografia levantada, como veremos à frente, uma tendência significativa de abordagem da temática do turismo rural. 
Tabela 14 - Palavras-chave nas teses em geografia agrária do PPGEO/UNESP/Rio Claro

\begin{tabular}{l|c}
\hline Palavras-chave & Total \\
\hline Agricultura & 7 \\
Estado & 6 \\
Modernização da Agricultura & 6 \\
Agroindústria & 4 \\
Espaço Agrário & 3 \\
Espaço Rural & 3 \\
Paraná & 3 \\
Políticas Públicas & 3 \\
São Paulo & 3 \\
Sergipe & 3 \\
Turismo & 3 \\
Agricultura Familiar & 2 \\
Campesinato & 2 \\
Cidade & 2 \\
Desenvolvimento & 2 \\
Desenvolvimento Regional & 2 \\
Região & 2 \\
Reprodução Social & 2 \\
Território & 2 \\
Uso da Terra & 2 \\
Outras & 1 \\
\hline Total & 63 \\
\hline
\end{tabular}

Fonte: Dissertações e teses em geografia agrária / USP / UNESP-RC / UNESP-PP / UERJ / UFF/UFRJ / UFU /UFMG.

Org. FERREIRA, D. Ap. O; VALLE, M. R.; ROMANATTO, M. J., 2010.

\section{c) USP}

Na análise do Programa de Pós Graduação da USP, a principal palavra-chave referenciada é São Paulo, fato que denota uma grande atenção dispensada a este local de pesquisa uma vez que outros locais aparecem, mas com uma frequência menor. Temos: Amazônia, Mato Grosso, Rio Grande do Sul, Pará, Paraná, Pantanal e Rondonópolis.

Notamos uma semelhança entre os Programas da USP e da UNESP de Presidente Prudente. Por um lado, duas das principais palavras-chave remetem ao estudo da questão agrária: campesinato e reforma agrária; e, por outro duas delas dizem respeito à abordagem da questão agrícola: agroindústria e modernização da agricultura. Se trouxermos novamente à tona a discussão dos autores-orientadores, devemos lembrar que vários orientadores da UNESP de Presidente Prudente, concluíram suas dissertações e teses na USP. 
No que tange à presença das categorias geográficas, notamos a incidência das palavras-chave: territorialidade, organização do espaço, espaço agrário, lugar, território, espaço rural, paisagem; todas citadas duas vezes ou mais (Tabela 15).

Tabela 15 - Palavras - chave nas dissertações em geografia agrária do PPGEO/USP

(Continua)

\begin{tabular}{|c|c|}
\hline Palavras-chave & Total \\
\hline São Paulo & 14 \\
\hline Campesinato & 11 \\
\hline Reforma Agrária & 11 \\
\hline Agroindústria & 7 \\
\hline Modernização da agricultura & 7 \\
\hline Uso da terra & 7 \\
\hline Geografia Humana & 6 \\
\hline Territorialidade & 6 \\
\hline Amazônia & 5 \\
\hline Movimento social & 5 \\
\hline MST & 5 \\
\hline Organização do espaço & 5 \\
\hline Pequeno produtor & 5 \\
\hline Urbanização & 5 \\
\hline Assentamento rural & 4 \\
\hline Café & 4 \\
\hline Cana-de-açúcar & 4 \\
\hline Colonização & 4 \\
\hline Espaço agrário & 4 \\
\hline Mato Grosso & 4 \\
\hline Relação de produção & 4 \\
\hline Relação de trabalho & 4 \\
\hline Rio Grande do Sul & 4 \\
\hline Trabalho Rural & 4 \\
\hline Agricultura & 3 \\
\hline Capitalismo & 3 \\
\hline Geografia Agrária & 3 \\
\hline Geografia Econômica & 3 \\
\hline Lugar & 3 \\
\hline Modo de vida & 3 \\
\hline Pecuária & 3 \\
\hline Rondonópolis & 3 \\
\hline Território & 3 \\
\hline Trabalho Feminino & 3 \\
\hline Agropecuária & 2 \\
\hline Atividade agrária & 2 \\
\hline Cerrado & 2 \\
\hline Cinturão verde & 2 \\
\hline Colonização japonesa & 2 \\
\hline Comunidades tradicionais & 2 \\
\hline Conflito & 2 \\
\hline
\end{tabular}


Tabela 15 - Palavras - chave nas dissertações em geografia agrária do PPGEO/USP

(Conclusão)

\begin{tabular}{l|c}
\hline Palavras-chave & Total \\
\hline Cultura & 2 \\
Espaço Rural & 2 \\
Estado & 2 \\
Expropriação & 2 \\
Fronteira & 2 \\
Geografia-Paraná & 2 \\
Laranja & 2 \\
Luta pela Terra & 2 \\
Migração & 2 \\
Ocupação do espaço & 2 \\
Paisagem & 2 \\
Pantanal & 2 \\
Pará & 2 \\
Paraná & 2 \\
Parceria & 2 \\
Plantas cultivadas & 2 \\
Políticas Públicas & 2 \\
Relação campo-cidade & 2 \\
Santa Catarina & 2 \\
Trabalhador rural & 2 \\
Trabalho & 2 \\
Transformações agrárias & 2 \\
Outras & 1 \\
\hline Total & 22 \\
\hline
\end{tabular}

Fonte: Dissertações e teses em geografia agrária / USP / UNESP-RC / UNESP-PP / UERJ / UFF/UFRJ / UFU /UFMG.

Org. FERREIRA, D. Ap. O; VALLE, M. R.; ROMANATTO, M. J., 2010.

Nas teses, encontramos, como constata a tabela 16, a referência preponderante às palavras-chave: campesinato, assentamento rural, luta pela terra, delineando o perfil de pesquisas deste Programa. Em seguida, aparece a palavra-chave: geografia agrária que, assim como no Programa de Pós Graduação da UFRJ, ocorre de forma pouco frequente. Nessa tendência podemos ainda citar: pensamento geográfico e geografia econômica como palavras referenciadas nas teses da USP.

As categorias geográficas que mais se destacam são: território, espaço, espaço agrário, organização do espaço e referências como: análise espacial, análise regional, territorialidade, paisagem, regionalização.

Com relação à temática da agricultura e suas diversas abordagens encontramos palavras-chave dentre as quais se destacam: agroindústria; modernização da agricultura; pequena produção; uso da terra e referência a culturas: café, cana-de -açúcar e soja. 
Tabela 16 - Palavras-chave nas teses em geografia agrária do PPGEO/USP

\begin{tabular}{|c|c|}
\hline Palavras-chave & Total \\
\hline Campesinato & 14 \\
\hline Assentamento rural & 5 \\
\hline Geografia Agrária & 5 \\
\hline Luta pela terra & 5 \\
\hline São Paulo & 5 \\
\hline Território & 5 \\
\hline Agroindústria & 4 \\
\hline Conflito & 4 \\
\hline Modernização da agricultura & 4 \\
\hline Reforma Agrária & 4 \\
\hline Trabalho & 4 \\
\hline Agricultura & 3 \\
\hline Café & 3 \\
\hline Cana-de-açúcar & 3 \\
\hline Capital & 3 \\
\hline Espaço agrário & 3 \\
\hline Pecuária & 3 \\
\hline Pensamento geográfico & 3 \\
\hline Pequena produção & 3 \\
\hline Violência & 3 \\
\hline Agricultura familiar & 2 \\
\hline Cooperativa & 2 \\
\hline Desenvolvimento sustentável & 2 \\
\hline Espaço & 2 \\
\hline Estratégias & 2 \\
\hline Fronteira & 2 \\
\hline Geografia Econômica & 2 \\
\hline Indicadores socioeconômicos & 2 \\
\hline Mato Grosso & 2 \\
\hline Movimento social & 2 \\
\hline MST & 2 \\
\hline Organização do espaço & 2 \\
\hline Políticas públicas & 2 \\
\hline Soja & 2 \\
\hline Subordinação & 2 \\
\hline Terra & 2 \\
\hline Terras de uso comum & 2 \\
\hline Transformação & 2 \\
\hline Uso da terra & 2 \\
\hline Outras & 1 \\
\hline Total & 125 \\
\hline
\end{tabular}

Fonte: Dissertações e teses em geografia agrária / USP / UNESP-RC / UNESP-PP / UERJ / UFF/UFRJ / UFU /UFMG.

Org. FERREIRA, D. Ap. O; VALLE, M. R.; ROMANATTO, M. J., 2010.

\section{Considerações Finais}

A proposta de fazer uma leitura teórico-metodológica da geografia agrária brasileira nos Programas de Pós-Graduação em Geografia (PPGEO’s) da Região 
SUDESTE, a partir dos anos 1970, por meio da discussão sobre as categorias de análise ( espaço, território, paisagem, região e lugar) que vem sendo desencadeada ao longo dos Encontros de Geografia Agrária (ENGA's) e nos três Encontros dos Grupos de Pesquisa de Geografia Agrária (2005, 2006, 2007) possibilitou tecer considerações significativas, sobretudo com relação a espaço, território e paisagem.

Assim, na leitura sobre as Categorias ficou evidenciado que a década de 1980 é marcada por uma atenção prioritária com a análise do espaço referenciado em suas diversas formas de organização. Nesse sentido, a Geografia Agrária vai utilizar a expressão Organização do Espaço Agrário com uma grande frequência. Merece destaque o Programa da UNESP de Rio Claro em que as dissertações e teses trabalharam com distintas organizações do espaço agrário, distribuídas ao longo do território nacional.

Ao mesmo tempo em que há um destaque para a organização espacial, em contrapartida a Paisagem é uma categoria não referenciada no escopo da pesquisa.

Na atualidade, o Território, e suas expressões derivadas, é a categoria mais freqüente nos trabalhos analisados, sob a ótica da apropriação/dominação e não na perspectiva jurídico-política. Ela é fartamente utilizada nos Programas de Pós Graduação da USP e da UNESP de Presidente Prudente.

Quanto aos Princípios Lógicos, também objeto de interpretação, constatamos que há nos trabalhos a preocupação de localizar o fenômeno - Agricultura - estudado, sem, contudo, serem feitas alusões à distribuição, extensão, escala. Notamos, dessa forma, que os princípios lógicos da geografia clássica passam por uma profunda transformação, sendo substituídos pelas noções e conceitos vinculados ao pluralismo teórico-metodológico marcante em nossa atualidade.

Sobre os Parâmetros Geográficos nos estudos de Agricultura, a interdisciplinaridade tem ocupado um espaço cada vez maior nas dissertações e teses dos diversos programas estudados, com ênfases diferenciadas, fato que, por um lado, muito contribui para que se abranja a Agricultura em seu amplo espectro, mas por outro lado, a Descrição, princípio fundante da própria geografia tem estado ausente do horizonte acadêmico. A preocupação com o fato a ser estudado tem sido priorizada com relação ao impacto que ele possa causar ao Espaço Geográfico. 
Diante dessas considerações, podemos inferir que a discussão sobre as categorias espaço, território e paisagem e dos princípios lógicos ainda podem ser mais explorados nos trabalhos de Geografia e, de forma específica, na Geografia Agrária uma vez que a agricultura, por sua própria complexidade e diversidade socioespacial requer uma abordagem interdisciplinar. Isso ficou evidente tanto nas diferentes abordagens teóricas e metodológicas, como até mesmo no delineamento da localização do objeto de estudo e da sua área.

\section{Notas}

1Este trabalho é resultado do Projeto ESPAÇO, TERRITÓRIO E PAISAGEM: uma leitura teóricometodológica da Geografia Agrária brasileira na pós-graduação a partir dos anos 1970 - Processo no. 400826/2008/2009, desenvolvido no período de junho/2008 a julho/2010 sob fomento do CNPq e foi apresentado no VI Encontro de Grupos de Pesquisa (ENGRUP)-UNESP/Presidente Prudente/ maio 2011.

$2 \mathrm{O}$ V Encontro de Grupos de Pesquisa realizado na UFSM/nov.2009 não foi considerado porque o levantamento de dados foi feito de 1970 a junho/2009.

\section{Referências}

DINIZ, José Alexandre F. Geografia da agricultura. São Paulo: DIFEL, 1984.

HAESBAERT, Rogério. Territórios alternativos. Niterói: EdUFF; São Paulo: Contexto, 2002.

MOREIRA, Ruy. Pensar e ser em geografia: ensaios de história, epistemologia e ontologia do espaço geográfico. São Paulo: Contexto, 2007.

SANTOS, Milton. Da teoria à prática: um modelo analítico. Metamorfoses do espaço habitado. São Paulo: HUCITEC, 1996. p.111-117.

\section{SITES DAS UNIVERSIDADES}

PROGRAMA DE PÓS-GRADUAÇÃO EM GEOGRAFIA. Corpo Docente. Disponível em: http://www.ufmg.br/pos/geografia/. Acesso em: 20 jun. 2009.

PROGRAMA DE PÓS-GRADUAÇÃO EM GEOGRAFIA. Apresentação. Disponível em: http://www.posgrad.ig.ufu.br/. Acesso em: 20 jun.2009.

PROGRAMA DE PÓS-GRADUAÇÃO EM GEOGRAFIA. Institucional, 2010. Disponível em: http://www.ppgg.igeo.ufrj.br/. Acesso em mar.2010.

PROGRAMA DE PÓS-GRADUAÇÃO EM GEOGRAFIA. Histórico; Doutorado;

Mestrado. Disponível em: http://www.uff.br/posgeo/. Acesso em: 20 em jun.2009. 
PROGRAMA DE PÓS-GRADUAÇÃO EM GEOGRAFIA. Sobre o Programa.

Disponível em: http://www.ppgeo.igeog.uerj.br/programa.php. Acesso em: 20 jun.2009.

PROGRAMA DE PÓS-GRADUAÇÃO EM GEOGRAFIA. Apresentação. Disponível em: http://www.geografia.fflch.usp.br/index.htm. Acesso em: 20 jun.2009.

PROGRAMA DE PÓS-GRADUAÇÃO EM GEOGRAFIA. Histórico, 2009.

Disponível em: <http://www.rc.unesp.br/igce/newpos/new_geo/historico.php>. Acesso em: 20 jun.2009.

PROGRAMA DE PÓS-GRADUAÇÃO EM GEOGRAFIA. Home. Disponível em: http://www4.fct.unesp.br/pos/geo/index.php. Acesso em: 20 jun.2009.

Enviado para publicação em junho de 2011.

Aceito para publicação em julho de 2011. 